\title{
The use of ECAP in the Microstructural Conditioning of the 355 Aluminum Alloy for Thixoforming ${ }^{\dagger}$
}

\author{
A. Gregolin ${ }^{a}$, C. A. Facchini ${ }^{b}$, E. J. Zoqui ${ }^{a *}$ (1) \\ ${ }^{a}$ Universidade Estadual de Campinas- UNICAMP, Escola de Engenharia Mecânica, Departamento de \\ Materiais e Fabricação, Campinas, SP, Brasil. \\ ${ }^{b}$ Instituto Federal de Educação Ciência e Tecnologia de São Paulo (IFSP), São João da Boa Vista, SP, \\ Brasil
}

Received: March 31, 2020; Revised: June 24, 2020; Accepted: August 21, 2020

\begin{abstract}
The purpose of this study is to analyze the use plastic deformation (ECAP - Equal Channel Angular Pressing) in the preparation of the 355 aluminum for posterior use in Thixoforming. For this purpose, the 355 alloy, in the as cast state and after a pass of ECAP was heated to temperatures of 575 and $595{ }^{\circ} \mathrm{C}$, enough to produce 45 and $55 \%$ of liquid fraction, for times of $0,30,60 \mathrm{e} 90 \mathrm{~s}$. In these conditions, it is possible to obtain a refined globular structure with the size of a grain, close to $75 \mu \mathrm{m}$, globule size of $55 \mu \mathrm{m}$ and high sphericity (around 0.66 ), parameters which are excellent for this kind of processing. Hot compression tests at the same temperatures and holding times determine the rheological behavior. Maximum processing strain was obtained around $1 \mathrm{MPa}$ for the sample in ECAped condition against $4 \mathrm{MPa}$ of the as cast condition, which corresponds to maximum viscosity around $10^{5} \mathrm{~Pa} . \mathrm{s}$, (molten glass, clay), inferior to the as cast condition $\left(11.5 * 10^{5} \mathrm{~Pa} . \mathrm{s}\right)$. Therefore, the ECAPed 355 alloy is an easily conformable material very likely to be applied to semisolid processing.
\end{abstract}

Keywords: Thixoforming, Semisolid material, Rheology, ECAP, 355 aluminum alloy.

\section{Introduction}

In the 1970s, during the development of a doctoral research on hot cracking in castings using the $\mathrm{Sn}-15 \% \mathrm{~Pb}$ alloy, Spencer, supervised by Merton Flemings ${ }^{1,2}$, found, for the first time, that the vigorous stirring during solidification significantly affected the dendritic morphology of the alloy, leading to the breakdown of dendritic branches. These dendritic branches lead to a globular or quasi-globular microstructure, surrounded by a liquid secondary phase that works like a semisolid state lubricant. This peculiar solid/ liquid mixture makes the semisolid metal alloy behave like a non-Newtonian and thixotropic ${ }^{1-3}$ viscous materials. The slurry is then formed in a mushy state and then solidified, presenting a final non-dendritic structure which guarantees the possibility of manufacturing components near-net-shape, with good mechanical properties, and a reduced number of flaws, such as porosity and contraction cracks ${ }^{4}$.

Thixoforming of metal alloys implies forming a mass comprised of refined grains, consisting of a primary phase, dispersed in liquid. Therefore, the understanding of phase transformation, microstructure stability, and viscous behavior of the slurry is fundamental for the development of these processes. Rheocasting and Thixoforming are the denominations of processes of forming metals alloys in the semisolid state, and the main requirements for these processes are a) thermodynamics - controllable solid liquid

\footnotetext{
*E-mail: zoqui@fem.unicamp.br

${ }^{\dagger}$ This paper was presented in the 10th Brazilian Congress on Manufacturing Engineering, August 2019, São Carlos / SP
}

transition; b) refined and globularized morphology and c) behavior of viscous fluid ${ }^{5}$.

The main objective of this work is to improve the thixoforming process of the 355 aluminum alloy as previous studies indicated excellent controllable thermodynamic ${ }^{6,7}$ behavior, but difficulties concerning morphology that does not respond well to grain chemical refining. It is also reported that 355 alloy has excellent mechanical properties with a yield strength of $230 \mathrm{MPa}$, ultimate tensile strength of $320 \mathrm{MPa}$ and an elongation of up to $7 \%$ after solubilization and aging heat treatment ${ }^{5}$.

In terms of quality of the SSM slurry, and therefore the rheological behavior, the so called SIMA (strain induced melt activation) processes ${ }^{8}$, are amongst of the most reliable in providing a mixture of small spherical particles immersed in liquid. In order to achieve this refined microstructure, several techniques such as cold rolling ${ }^{9}$ and extrusion ${ }^{10}$ can be used, previously to the semisolid processing, in such a way that the deformed material will pass throughout recuperation, recrystallization and partial melting of the grain boundary during the heating to the semisolid state ${ }^{8,9}$. The deformation via ECAP (equal channel angular pressing) is one of the plastic deformation techniques that aims to refining the grain through plastic deformation, promoting an increase in the final mechanical strength of the product, and can be a possible route for the production of raw material for $\mathrm{SSM}^{11-13}$. The advantage in using ECAP is that, with only one pass the deformation is severe enough to produce a homogeneous SSM slurry ${ }^{11-13}$. Besides, the work analyzes the rheology of 355 aluminum alloy, using hot compression test in semisolid state and after submitted to ECAP in comparative terms. 


\section{Experimental Procedure}

The 355 alloy was produced with mass balance using the A356 as base alloy, by adding commercially pure aluminum ( $\mathrm{Al} \mathrm{cp}$ ) and commercially pure copper $(\mathrm{Cu} \mathrm{cp})$. The chemical analysis of the raw material was done with an optical emission spectrometer Bill-Oes model (Anacom Cientifica). Table 1 presents the composition of the as cast 355 , as well as the lower and upper limits prescribed by the ASTM B179-14 ${ }^{14}$ standards.

The material was melted in a resistive furnace in a $\mathrm{SiC}$ crucible pre-insulated by QF180 and the liquid was poured in a water-cooled copper mould to produce a $30 \mathrm{~mm}$ diameter and $260 \mathrm{~mm}$ long ingot from a $671^{\circ} \mathrm{C}\left(\mathrm{T}_{\text {liquidus }}=621^{\circ} \mathrm{C}^{6,7}\right)$ pouring temperature. The water flow in the copper mould was $35 \mathrm{l} / \mathrm{min}$ (Figure $1 \mathrm{a}$ and $1 \mathrm{~b}$ ).

Ingots with $30 \mathrm{~mm}$ diameter and $150 \mathrm{~mm}$ length were processed via ECAP. The Hydraulic Press used in ECAP, Figure 1c, supports 50 tons and operates with a maximum speed of $\sim 7 \mathrm{~mm} / \mathrm{s}$. The $\mathrm{H} 13$ steel die (tempered and annealed) is split forming a cylindrical channel with $30 \mathrm{~mm}$ diameter (Figure 1d) in two sections. The two sections form a $120^{\circ}$ degree angle. The die also has an external heating system that keeps the system at a temperature of $150^{\circ} \mathrm{C}$ and avoids recrystallization of the material, which occurs above $320^{\circ} \mathrm{C}$.

The characterization of the 355 alloy work temperatures was done in a previous study, using the following methods: computational simulation, with the use of the Thermo-Calc $\mathbb{R}$ software, DSC (Differential Exploratory Calorimetry) and DTA (Differential Thermal analysis) tests. Results then obtained recommend working in semisolid state within $575{ }^{\circ} \mathrm{C}$ and $605^{\circ} \mathrm{C}^{6,7}$. The ability to maintain the material in a pasty or thixotropic state when processing can be analyzed through the solidification interval and the use of the liquid fraction sensitivity concept considering the temperature $\left(\mathrm{df}_{\mathrm{L}} / \mathrm{dT}^{3,5}\right)$ in the interior of the semisolid range.

For the temperatures chosen for the post-ECAP processing at 575 and $595{ }^{\circ} \mathrm{C}$, and liquid fraction of 45 and $55 \%$, this sensitivity is 0.025 and $0.020^{\circ} \mathrm{C}^{-1}$, lower than recommended by the literature, which indicates a limit of $\mathrm{df}_{\mathrm{L}} / \mathrm{dT}<0.030$ ${ }^{\circ} \mathrm{C}^{-1}$ (Atkinson ${ }^{3}$ ). Two types of tests were carried out at these temperatures: evaluation of the thermo stability of the structure and hot compression tests.

The tests to evaluate the stability of the structure required heating of the samples with a $30 \mathrm{~mm}$ diameter and $30 \mathrm{~mm}$ height in an induction furnace with maximum temperature of $1.200{ }^{\circ} \mathrm{C}$ Norax $20 \mathrm{~kW}, 8 \mathrm{kHz}$. The internal diameter and height of the coil used are $85 \mathrm{~mm}$ and $75 \mathrm{~mm}$ respectively. The reheating temperatures and the holding time are controlled with a type K thermocouple (Chromel Alumel) coupled to the control system of the induction furnace. Previous works determined that a reheating test, using a heating rate of $100{ }^{\circ} \mathrm{C} / \mathrm{min}$ until it reached 575 e $595^{\circ} \mathrm{C}$, was to be carried out to obtain liquid fraction of 45 and $55 \%$ respectively, for 30 s and 60 s of treatment followed by water cooling. Figure 2 shows a photomontage of the system used.

The objective of this first heating test is to bring the ingot to semisolid state and obtain the liquid fraction desired to guarantee the globularization of the particles, making them spherical. Basically, Partial Controlled Melting (PCM) involves the heating of the material to temperatures higher than solidus temperature $\left(\mathrm{T}_{\text {solidus }}=505^{\circ} \mathrm{C}\right)$, promoting the melting of low melting point micro constituents, as

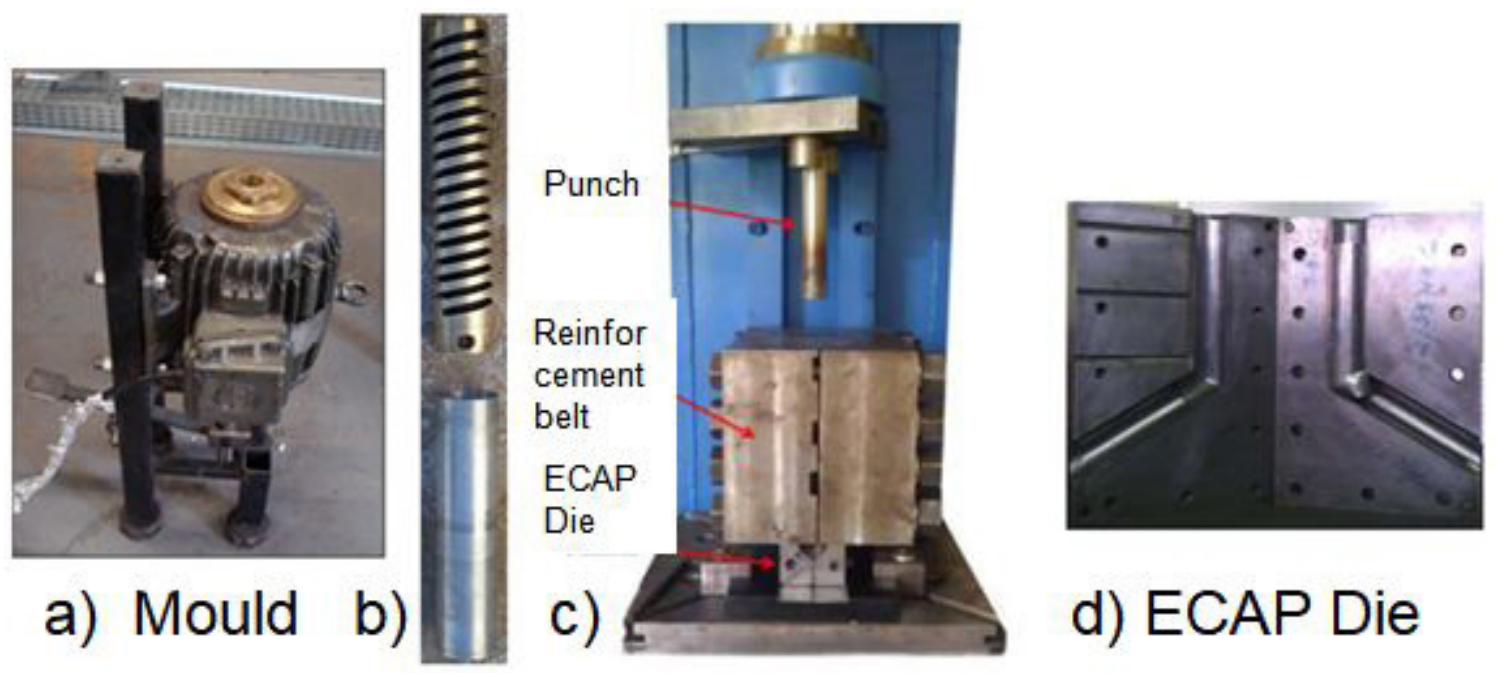

Figure 1. Photomontage showing: a) copper mould; b) internal cooling system of the mould; c) experimental setup of ECAP (punch and matrix reinforcement belt and d) ECAP die opened.

Table 1. Chemical composition of the 355 alloy used in this work (in wt $\%$ ).

\begin{tabular}{lcccccc}
\hline & $\mathbf{S i}$ & $\mathbf{C u}$ & $\mathbf{F e}$ & $\mathbf{M g}$ & $\mathbf{M n}$ & $\mathbf{A l}$ \\
\hline Composition & $5.02 \pm 0.26$ & $1.06 \pm 0.06$ & $0.23 \pm 0.02$ & $0.26 \pm 0.08$ & $0.10 \pm 0.05$ & Bal. \\
\hline Lower Limit & 4.5 & 1.0 & & 0.4 & & \\
\hline Upper Limit & 5.5 & 1.5 & 0.6 & 0.6 & 0.5 & \\
\hline
\end{tabular}




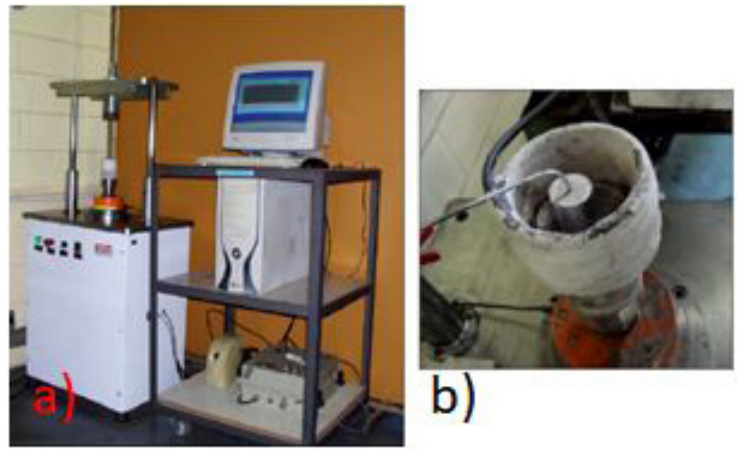

Figure 2. photomontage of the compressive rheometer showing the hot compression system in a) and a sample in the internal part of the inductive coil in b).

it happens in the eutectic phases of the hypoeutectic and hypereutectic alloys.

The micro structural characterization was performed with the electrolytic etching on the sanded and polished faces of the samples, using $\mathrm{HBF}_{4}$ (Fluoboric Acid) in a $2 \%$ solution, $27.5 \mathrm{~V}$ voltage, $0.25 \mathrm{~A}$ current, with a holding time of $300 \mathrm{~s}$, under moderate and constant stirring. An optical polarized light microscope (Leica DM ILM) was used, enabling the measurement of the average grain size (GS); while the microstructural characterization (conventional metallography), without the use of polarized light, generates black and white images of the primary phase in dendrite or globule morphology (GLS) and enables the calculation of its average circularity (Shape Factor - SF). Grains, in the as-cast or at the heated condition, that presents the same crystal orientation, appear as areas with similar colours and shades, making it easier to identify and characterize them at the polarized colour metallography. B\&W conventional characterization was used to evaluate the primary phase separately, which in the as-cast will appears in dendrite form and the intercept method gives the average dendrite arm spacing. In the as heated sample those dendrites will become "globules" surrounded by the eutectic phase and therefore the intercept method will give the average globule size. The average size of the grain and globule were measured by the Heyn Intercept Method, under the standards of the ASTM E112-13 ${ }^{15}$. The shape factor was obtained through software ImageJ 1.5e. This software highlights the grains boundaries of the image, attributing value that varies from 0 to 1 , in which value 1 is applied to the boundary with perfect circular shape.

The metallographic Rheocast Quality Index (RQI) developed by Zoqui et al. ${ }^{15}$ was used to qualify comparatively the globularization of the microstructure. This factor correlates morphological parameters with microstructural ones, allowing the analysis of the efficiency for the method of obtaining raw material used in the Thixoforming process. The calculation of the RQI factor is in Equation 1:

$$
R Q I=\frac{G L S}{G S} * S F
$$

Just as the shape factor, the RQI index varies between 0 and 1 , where value 0 implies a dendritic structure and value 1 is applied to the completely globularized structure, that is, the best morphology for the thixoforming process. The structural characterization is necessary as a parameter to verify how refined and globular the structure is, allowing better flow. The previous processing via ECAP, which forces the passage of the ingot through a matrix with angular channels, deforms the grains plastically, making them elongated with a low angle contour. Mechanical work distorts the sliding planes, causing part of the energy involved to be stored in the material, and part of it to be dissipated as heat, causing metastable balance. During the reheating of the samples (diameter and height of $30 \mathrm{~mm}$ ) at 575 or $595^{\circ} \mathrm{C}$ and holding at this temperature for $30 \mathrm{~s}$ or $60 \mathrm{~s}$, the mechanisms of recovery, recrystallization, coalescence and Ostwald Ripening occur. The holding of the material in semisolid state melts the grain boundary and the dendritic arms, transforming the structure into an almost perfectly globular shape, due to the need to reduce of superficial energy $y^{9,10}$.

The hot compression test determines the viscous behavior of the alloy studied. The rheometer has a $25 \mathrm{kN}$ capacity load cell (4 - $20 \mathrm{~mA} ; 2 \mathrm{mv} \mathrm{V-1; \pm 0.10 \%} \mathrm{FRO)} \mathrm{and} \mathrm{an} \mathrm{internal}$ LVDT displacement sensor (range: $200 \mathrm{~mm}$; repeatability: $2.5 \mathrm{~lm}$; non-linearity: $\pm 0.10 \% \mathrm{FRO}$ ) coupled to a USB 6210 National Instruments data acquisition system with a maximum data-acquisition rate of $5 \mathrm{k}$ readings $\mathrm{s}^{-1}$. Initially, the samples are reheated, kept at the temperature level for 30 or 60 s and then compressed. The system was adjusted to advance the piston with a nominal speed of $125 \mathrm{~mm} / \mathrm{s}$. The hot compression test between parallel plates is the most adopted and accepted method as a reference for rheological characterization, and one that best represents the mechanical forming used in industry ${ }^{4,15,16}$. In hot compression tests, displacement and force data are converted to engineering deformation versus strain. In Equation 2, using a cylindrical sample with initial height of $\left(H_{0}-\mathrm{mm}\right)$ and initial diameter of $\left(D_{0}-\mathrm{mm}\right)$, the engineering deformation $(e-\%)$ is obtained for a given time in compression and instant height of $(H-\mathrm{mm})$. The strain $(\sigma-\mathrm{MPa})$ at a given time $(t-\mathrm{s})$, during the test, is obtained according to Equation 3. The samples during the test have a constant volume $\left(V-\mathrm{mm}^{3}\right)$; also, the area between the parallel plates is bigger than the sample area after the deformation step ${ }^{16}$.

$$
\begin{gathered}
e=1-\left(\frac{H}{H_{0}}\right) \\
\sigma=\frac{F H_{0}}{V}(1-e)=\frac{F H}{V}
\end{gathered}
$$

The viscosity ( $\mu$ - Pa.s) and the average shearing rate $\left(\dot{\gamma}-\mathrm{s}^{-1}\right)$ due to time, as proposed by Laxmanan and Flemings ${ }^{16}$, are obtained according to Equations 4 and 5 respectively, considering the force applied $(F-\mathrm{N})$.

$$
\begin{gathered}
\mu(t)=\frac{-2 \pi h^{5} F(t)}{3 V^{2}(d h / d t)} \\
\dot{\gamma}=-\left(\sqrt{\frac{V}{\pi}}\right)\left(\frac{(d h / d t)}{2 H^{2,5}}\right)
\end{gathered}
$$




\section{Results and Discussion}

Figure 3 shows, respectively, the images of coloured metallography, using the image polarization technique and conventional black and white metallography for the microstructures of the as cast $(a, b)$ conditions as well as the samples from these ingots in the as-cast condition, however submitted to deformation as it went through only one ECAP (c,d) pass. In the as-cast condition, it is possible to clearly observe the existence of an irregular and almost coarse, (non-refined) structure formed by the classic primary phase, $\mathrm{Al}$ rich $\left(\alpha-\mathrm{Al}_{\mathrm{FCC}}\right)$, and the secondary eutectic phase, formed by a lamellar structure that intercalates silicon plates and the $\alpha-\mathrm{Al}_{\mathrm{FCC}}$, observed both in the boundary of the dendritic arms, that is, distributed intragranular, and in the grain boundary, i.e., intergranular. Small light gray structures, which are copper microprecipitates, notably $\mathrm{CuAl}_{3}{ }^{5}$, are also observed.

It is noteworthy that the coloured metallography allows a better visualization of the structure, morphology and size of the grains, while the conventional $\mathrm{B} \& \mathrm{~W}$ is more indicated to the proper visualization of the secondary eutectic phase, usually at higher magnification.

It was not observed refining effect in the secondary eutectic phase due ECAP processing. Note that there was not the addition of grain refiner (Aluminum-TitaniumBoron alloys) and silicon modifiers (Aluminum-Strontium alloys or sodium salts). The work presented here is done to evaluate exclusively the effect of the plastic deformation in the primary phase, although since that, in the present case, the deformation changes the format and distribution of the silicon, there is a positive side-effect that would imply in an improvement of the structure through its refinement together with the reduction and fragmentation of the silicon which, in general, will present the best mechanical properties.

The microstructure of the deformed alloy by ECAP, Figure $3 \mathrm{c}$ and $3 \mathrm{~d}$ presents grains that are still dendritic, but elongated according to the direction of deformation. The same can be observed in the conventional microstructure (Figure 3d) with a better visualization of the deformed secondary dendritic arms. The deformation does not change significantly the size of the grain. It only elongates it in the expected direction of deformation. However, it is observed that the dendritic structure presents small points of fragmentation along the deformation direction. Those areas were highlighted by a green circle (Figure 3c) shown specific areas were the thickness of the dendrite arm was diminish due deformation. When heated the material will recrystalize and lead to a situation where new grains will be formed, and if this structure reaches the semisolid state without a complete recrystallization these narrow areas can melt, breaking the dendritic grain.

Figure 4 presents the images, coloured and black and white microstructures, obtained after heating at the semisolid temperature $\left(595{ }^{\circ} \mathrm{C}\right)$, and maintaining for 30 and $60 \mathrm{~s}$,
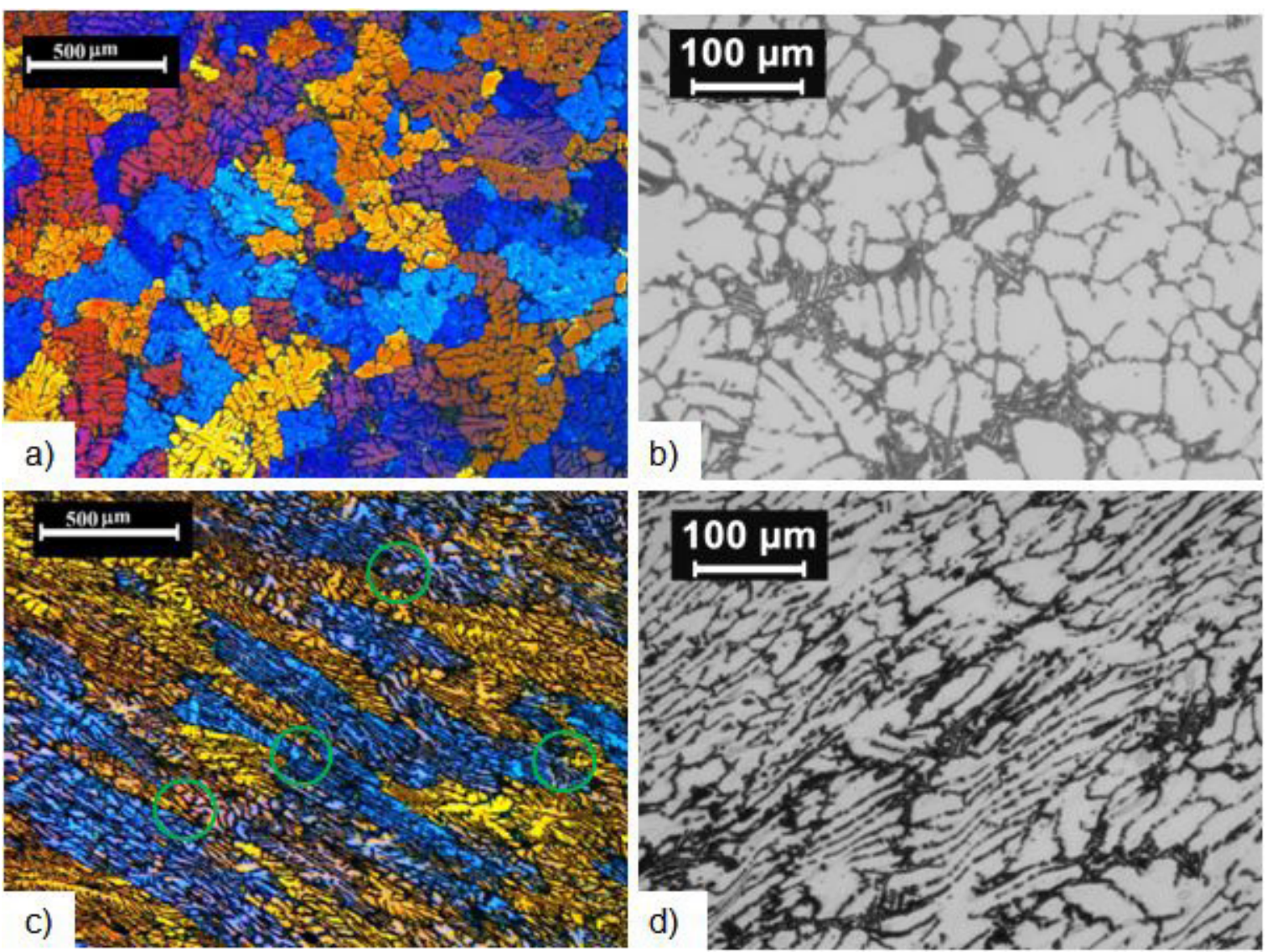

Figure 3. Polarized and conventional light micrograph of the samples in the as-cast (a, b) and as-ECAPed (c, d) for the 355 alloy respectively. 

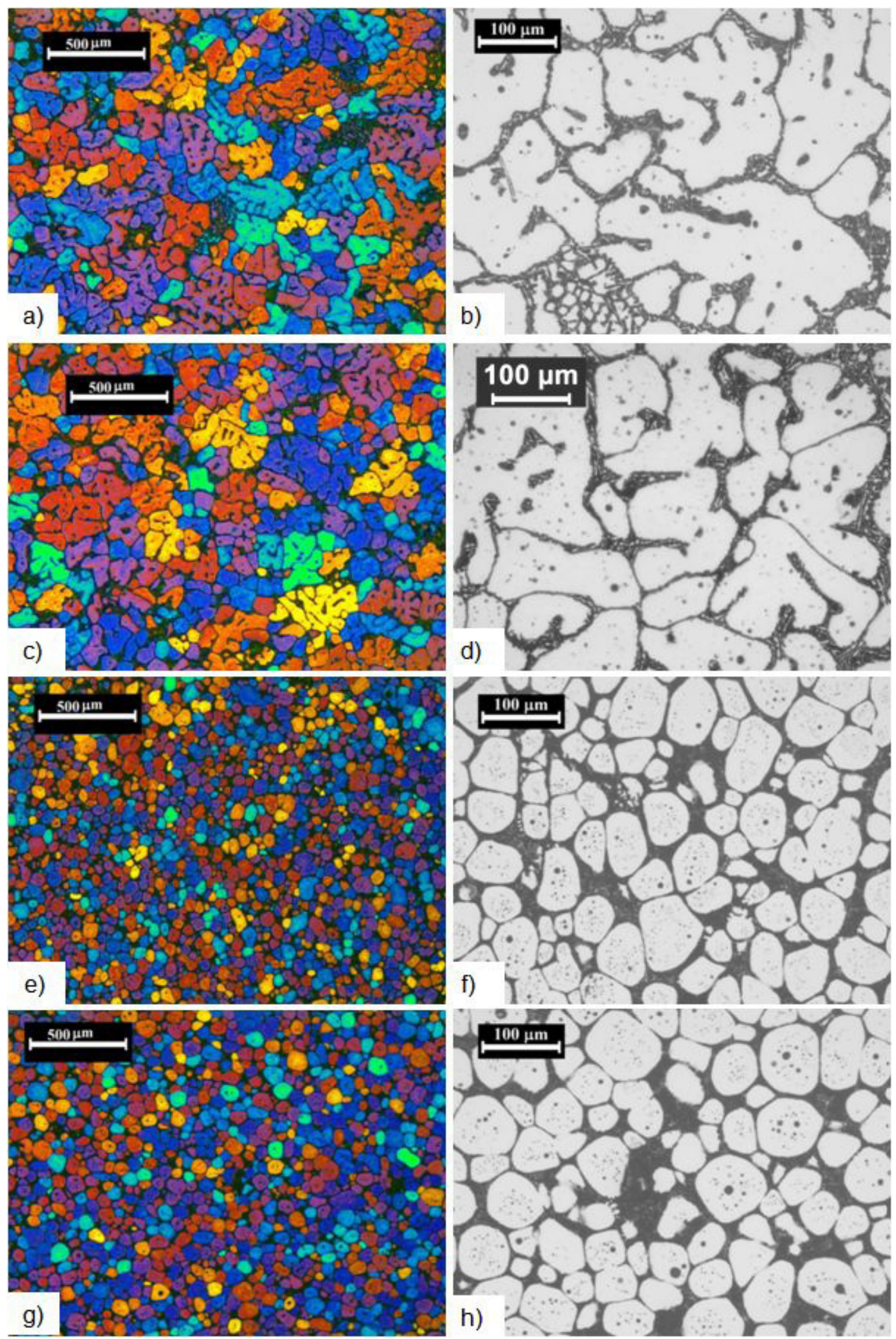

Figure 4. Coloured and B\&W micrographies of the 355 alloy heated to $595^{\circ} \mathrm{C}$, under holding times of 30 and $60 \mathrm{~s}$, obtained from the initial conditions as-cast (a, b, c, d) and after a only one ECAP deformation (e, f, g, H). 
samples of the material as-cast (a to d) and deformed by ECAP (e to h). Note that quasi-globularization occurs after heating from both initial conditions, generating a structure known as rosettes, however, the level of globularization is higher for the ECAPed samples. They present the smallest grain size, the smallest primary phase (globule) size, as well as the most globular morphology.

It is clear that plastic deformation gave rise to a much more refined structure regarding grain size, presenting a refined eutectic secondary phase without the use of refiners and silicon modifiers. Small globular-shaped precipitates, rich in silicon (dark black) and $\mathrm{CuAl}_{3}$ (light gray), can also be observed. In fact, the refinement of the secondary eutectic phase is confirmed by observing that the eutectic originated from the as-cast plus heating to the semisolid state is easily distinguishable while in the ECAPed plus heat treatment, the eutectic is not distinguishable, when observing with the same magnification, even both being submitted to the same cooling procedure after heat treatment. A possible explanation for this is that, the structure originating from the as-cast condition, with a more coarse morphology presents a wide spacing between branches of the remaining solid primary phase, which allows the eutectic to grow and form the lamellae of the $\mathrm{Al}_{\alpha}$ and silicon phases, without many barriers to this growth. In the case of the structure originating from the deformed samples, the area available for this growth is small, preventing the formation of well distinguishable lamellae, leading to an apparent refinement of this secondary phase. For the deformed structure, a more uniform rheological behavior, as well as a more reduced load application is expected, due to the fact that the liquid amongst particles, that is well distributed, will lubricate the movement of those small particles.

The results obtained in this work show that the solidification process of the 355 alloy, without interference of grain refiner, led to the formation of almost coarse, or less refined, grains with average size around $160 \mu \mathrm{m}$. Therefore, after the reheating of the samples at $595{ }^{\circ} \mathrm{C}$, for $30 \mathrm{~s}$ and $60 \mathrm{~s}$, the grains remained non-refined, whereas the primary phase globules enlarged considerably (via coalescence and Ripening mechanisms). In this case the heating to the semisolid state via partial melting causes the melting of the secondary eutectic phase present in the grain boundary as well as inside the grains and, while the liquid present in the grain boundary facilitates the detachment of the grains from each other and thus the breaking of the dendrite skeleton that keeps the structure to stand still, the liquid formed inside the grain, i.e., amongst the dendrite arms facilitate coarsening and ripening mechanisms, changing the morphology from dendritic to globular or rosette shape in order to diminish the surface energy of the remaining solid particle ${ }^{9}$.

This, however, did not happen to the deformed structure. In this case the material will first undergo the recovery phenomenon, followed by the recrystallization of the deformed grains, which will already be in a configuration of equiaxial grains surrounded by the eutectic secondary phase and, with the continuation of heating, there will be the partial melting of this eutectic present in the new grain boundary, generating a globular solid immersed in liquid and a consequent dismantling of this structure, which, hopefully, leads to a better and smooth flow of the slurry, ${ }^{9,12,13}$.

Table 2 shows the results obtained with the quantitative characterization of all the samples taken during the process. It is important to observe that only after the heating to semisolid state there is a $16 \%$ reduction of the average size of the grain in relation to the as-cast condition. That is, there is a fragmentation of the as-cast structure.

As mentioned before, heating makes the as-cast and the deformed ingot up to semisolid state in order to obtain the liquid fraction desired, ensuring the globularization of the particles, making them spherical. Basically, controlled partial melting involves heating the material at temperatures higher than solidus temperature $\left(\mathrm{T}_{\text {solidus }}=505^{\circ} \mathrm{C}\right)$, promoting the melting of phases with low melting point, as it occurs with the eutectic phases of the hypoeutectic and hypereutectic alloys.

Results of quantitative data presented in Table 2 shows that grains and globules of the ingot in the as-cast condition are very close in size to those deformed by ECAP, however, with the recrystallization that occurs during reheating, new smaller average size grains are formed. Nevertheless, the average size of the globule increases due to holding time at high temperature and the action of the mechanisms mentioned above, for both initial conditions. The mechanical work of plastic deformation in solid state distorts the sliding planes, causing a part of the energy involved to be dissipated as heat, whereas a small portion is stored in the material. The work stores up to $10 \%$ of the energy involved ${ }^{17}$. The energy accumulated is relieved during reheating, which acts as a driving force for the nucleation and growth of the grains through recrystallization. The boundaries of the grains are melted in lower temperatures (eutectic) and the material reaches semisolid state. The holding at temperatures higher than $\mathrm{T}_{\text {eutectic }}$, melting of boundaries of grains and dendrite arms modifies the morphology of the remaining solid to the globular structure observed, due to the need of reducing superficial energy, as mentioned early. Particles of the same size can coalesce to form larger ones, whereas the larger particles in saturated solutions grow incorporating smaller particles by diffusion through the Ostwald Ripening mechanism ${ }^{15}$.

Table 2. Average size of the grain (GS), globule (GLS), circularity (SF) and consequent Rheocast Quality Index for the 355 alloy as produced and heated to semisolid state.

\begin{tabular}{lcccc}
\hline \multicolumn{1}{c}{ Condition } & GS $(\boldsymbol{\mu m})$ & GLS $(\boldsymbol{\mu m})$ & SF & RQI \\
\hline As-Cast & $162 \pm 36$ & $53 \pm 12$ & $0.34 \pm 0.21$ & $0.11 \pm 0.17$ \\
\hline As-ECAPed & $164 \pm 46$ & $44 \pm 18$ & $0.22 \pm 0.25$ & $0.06 \pm 0.23$ \\
\hline Cast $@ 595{ }^{\circ} \mathrm{C} / 30 \mathrm{~s}$ & $142 \pm 27$ & $111 \pm 27$ & $0.44 \pm 0.20$ & $0.34 \pm 0.22$ \\
\hline Cast $@ 5955^{\circ} \mathrm{C} / 60 \mathrm{~s}$ & $140 \pm 19$ & $113 \pm 17$ & $0.43 \pm 0.19$ & $0.35 \pm 0.24$ \\
\hline ECAPed $@ 595^{\circ} \mathrm{C} / 30 \mathrm{~s}$ & $74 \pm 9$ & $56 \pm 5$ & $0.65 \pm 0.17$ & $0.49 \pm 0.12$ \\
\hline ECAPed $@ 595^{\circ} \mathrm{C} / 60 \mathrm{~s}$ & $74 \pm 9$ & $57 \pm 6$ & $0.66 \pm 0.18$ & $0.51 \pm 0.12$ \\
\hline
\end{tabular}


Thus, 355 alloy can be thermodynamically transformed into semisolid state and controlled for thixoforming according to the parameters used in this work. The ingot reheated after an ECAP pass exhibits the best RQI average index, which indicates the best viscosity for working in the semisolid state. The forming of the material with this morphology index should reduce the number of defects generated after the solidification of the part produced. The structure with reduced grain size, globular size and homogeneous eutectic distribution can provide excellent mechanical properties to the final product.

The thixotropic material in rest condition remains stable. When shearing begins, the material deforms continuously and fluidly at very low strain. In general, the shear stress reaches a small peak, which implies the breaking of the weak forces that unite the globules and the grains, which in rest state form a fragile skeleton. Strain reduces gradually until reaching an equilibrium value that occurs for high shear rates over the time of load application ${ }^{1,7,9,10,14,15}$. The higher the shear rate imposed after this peak, the lower the equilibrium viscosity. To illustrate this phenomenon, Figure 5 shows samples from the worst condition, that is, the one that is just partially melted after going through the hot compression test in the conditions a) $575{ }^{\circ} \mathrm{C}$ (temperature lower than indicated for processing, that should be higher than $581.3^{\circ} \mathrm{C}$ according to Brollo ${ }^{6}$ ) and b) $595^{\circ} \mathrm{C}$, both after holding time at the semisolid temperatures for $60 \mathrm{~s}$ and heating rate of $100^{\circ} \mathrm{C} / \mathrm{min}$. Note that there was only semisolid flow in the sample processed at higher temperature. The processed sample at lower temperature does not flow uniformly once the skeleton that interconnects the remaining solid still exists.

a)

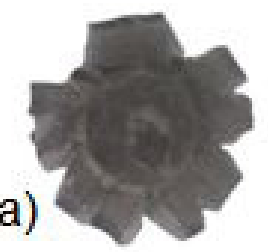

b)

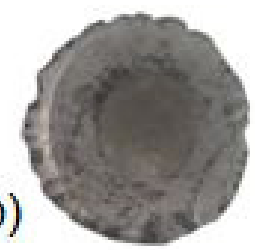

Figure 5. Image of the cast condition after hot compression tests carried out at a) $575^{\circ} \mathrm{C}$ and b) $595^{\circ} \mathrm{C}$. Heating rate of $100^{\circ} \mathrm{C} / \mathrm{min}$ and holding time at semisolid temperature of $60 \mathrm{~s}$, for both cases.
Figure 6 presents the graphs stress $\mathrm{x}$ strain (a) and apparent viscosity $\mathrm{x}$ shear rate (b) generated with data from hot compression tests. The rheological behavior is the typical behavior for SSM processing ${ }^{1-4,18,19}$ : material stay at rest without shear; when shearing starts occurs the increasing of the viscosity and stress and at higher shear rate the diminishing of stress and viscosity, even for slurries with high RQI. Low stress generating low viscosity even when high deformations are applied, as can be seen in the rheological behavior of those samples previously submitted to high deformation by ECAP to produce fine and spherical globules: in this case $80 \%$ strain, that correspond to $6.5 \mathrm{~s}^{-1}$ shear rate generates stress of $650 \mathrm{kPa}$ or $10^{5} \mathrm{~Pa}$.s. It was also observed that the structure obtained from as-cast condition presents, at higher temperature $\left(595^{\circ} \mathrm{C}\right)$, similar flow behavior to the structure produced from ECAP with higher solid fraction, that is, at $575^{\circ} \mathrm{C}$, therefore both fraction liquid as well as the morphology of the primary phase is extremely important in thixoforming ${ }^{1-4,12,18}$. However, the ECAP sample at $595^{\circ} \mathrm{C}$ flows easily, reaching maximum forming stress of only 1 MPA and viscosity of only $10^{5} \mathrm{~Pa}$.s (similar to clay - Flemings ${ }^{1}$ ). Still, no significant effect of the holding time were observed, in fact as shown at Table 2 the difference of the maintenance of the semisolid material at morphology

Continuing, there was no significant effect of the heattreatment time at semisolid temperature on the rheological behavior. This can be seen in the insignificant change in the morphology of the tested structures. For this short interval, from 30 to $60 \mathrm{~s}$ holding time, there is no significant change in grain, globule size or in the shape of the solid particles. However, there is a pronounced effect due to the size and shape of the particles, samples with about $140 \mu \mathrm{m}$ of grain size presents four times the maximum strain for forming, and apparent viscosity ten times higher for the same condition of the sample with about $75 \mu \mathrm{m}$ grain size. In general, an increase from 0.35 to 0.50 in RQI had a significant effect on rheology.

It is also observed that, as previously presented by Kang et al. ${ }^{19}$, there is expelling of the liquid by the solid from the central part of the sample to its side. In the present case liquid segregation was observed in the samples cast at $595^{\circ} \mathrm{C}$ and for the ECAPed at $575^{\circ} \mathrm{C}$ for 30 and $60 \mathrm{~s}$ holding time, but it was not observed for the ECAPed at $595{ }^{\circ} \mathrm{C}$ in both
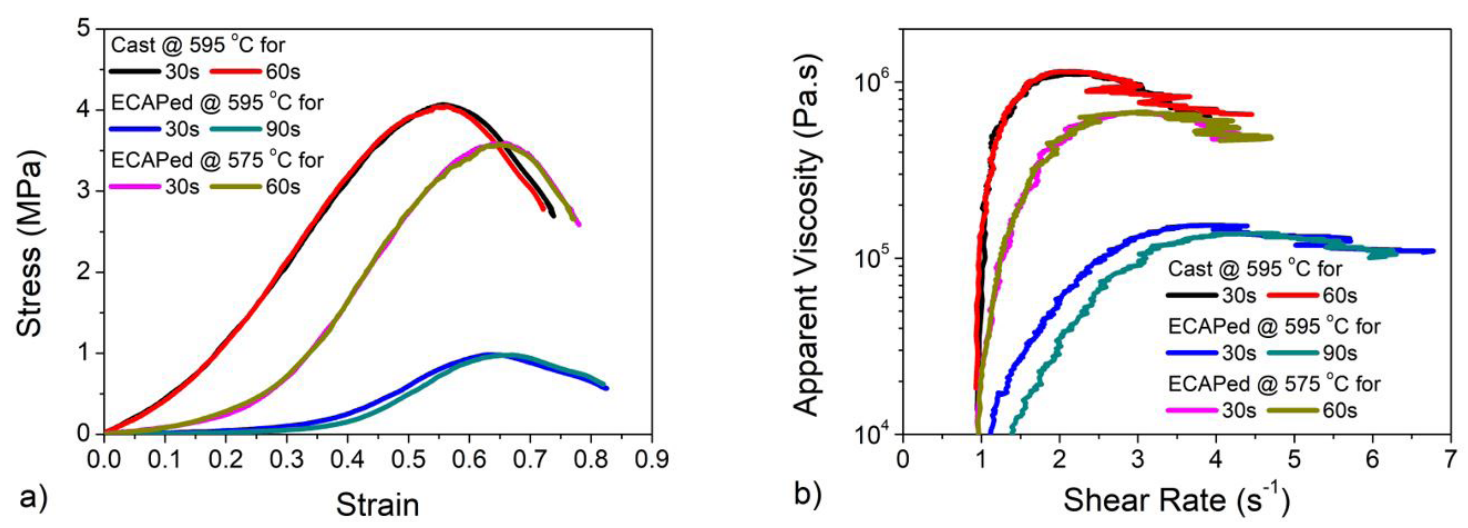

Figure 6. Stress x strain curves (a) and apparent viscosity x shear rate (b) for the 355 alloy in the semisolid state at $575^{\circ} \mathrm{C}$ and $595^{\circ} \mathrm{C}$, after holding time for 30 and $60 \mathrm{~s}$. Semisolid material obtained from cast and ECAPed conditions, as indicate. 
holding times. Usually higher shear rates are recommended to avoid this separation ${ }^{3,4}$. However, the conditioning of the microstructure through plastic deformation generates microstructure and consequent rheology, ideal for thixoforming processing without this separation. Usually, solid forming of these alloys are performed under stress above $120 \mathrm{MPa}^{\mathrm{x}}$, whereas in the semisolid state only $1 \mathrm{MPa}$ was necessary to generate $80 \%$ deformation in the sample. Therefore, it can be concluded that previous processing via ECAP on the production of aluminum alloys with high silicon content for further processing in semisolid state is an excellent process alternative route in spite of the inclusion of a process step.

\section{Conclusions}

The 355 alloy responded excellently to the microstructure conditioning through plastic deformation (ECAP). A refined microstructure with grain size decreasing from 160 to only $70 \mu \mathrm{m}$, globule size around $65 \mu \mathrm{m}$, and shape factor of 0.65 (highly globularized shape), which generated forming stress around $1 \mathrm{MPa}$ and apparent viscosity of $10^{5} \mathrm{~Pa}$.s, similar to molten glass or clay indicates excellent formability in the semisolid state and a good solution for parts production. And further, after processing mechanical properties could be improved via solubilization and aging heat treatment, leading the thixoformed 355 alloy as excellent material for complex mechanical parts that requires low weight.

\section{Acknowledgements}

The authors are very thankful to the Brazilian research agencies CNPq (National Council for Scientific and Technological Development - PQ 304921 / 2017-3), FAPESP (São Paulo Research Foundation - Project 2015 / 22143-3), and CAPES (Coordination for the Improvement of Higher Education Personnel - Brazil) - Financial Code 001), for providing financial support for this study.

\section{References}

1. Flemings MC, Riek RG, Young KP. Rheocasting. Mater Sci Eng. 1976;25:103-17. http://dx.doi.org/10.1016/0025-5416(76)900574.

2. Flemings, M.C. Behavior of metal alloys in the semisolid state. Metall Trans, A, Phys Metall Mater Sci. 1991;22A:957-81. http://dx.doi.org/10.1007/BF02661090.

3. Atkinson HV. Modelling the semisolid processing of metallic alloys. Prog Mater Sci. 2005;50(3):341-412. http://dx.doi. org/10.1016/j.pmatsci.2004.04.003.

4. Lashkari O, Ghomashchi R. The implication of rheology in semisolid metal processes: an overview. J Mater Process Technol. 2007;182(1-3):229-40. http://dx.doi.org/10.1016/j. jmatprotec.2006.08.003.
5. Zoqui, E.J. Alloys for semisolid processing. Comprehensive Materials Processing. 2014;5:163-90. http://dx.doi.org/10.1016/ B978-0-08-096532-1.00520-3.

6. Brollo GL, de Paula LC, Proni CTW, Zoqui EJ. Analysis of the thermodynamic behavior of A355 and B319 alloys using the differentiation method. Thermochim Acta. 2018;659:121-35. http://dx.doi.org/10.1016/j.tca.2017.11.011.

7. Paula LC, Brollo GL, Proni CTW, Zoqui EJ. Thixoformability analysis of 355 aluminum alloy. Metallography, Microstructure, and Analysis. 2018;7(1):48-56. http://dx.doi.org/10.1007/ s13632-017-0411-4.

8. Tzimas, E., Zavaliangos, A. Comparative characterization of near-equiaxed microstructures as produced by spray casting, magneto hydrodynamic casting and the stress induced, melt activated process. Mater Sci Eng A. 2000;289A(1):217-27. http://dx.doi.org/10.1016/S0921-5093(00)00907-2.

9. Zoqui EJ, Robert MH. Contribution to the study of mechanisms involved in the formation of rheocast structure. J Mater Process Technol. 2001;109(1-2):215-9. http://dx.doi.org/10.1016/ S0924-0136(00)00798-6.

10. Fiorini, P., Zanardi, L., Pellegrini, V. Primary and wrought products for semisolid forming of aluminium alloys. Metall Ital. 1994;86(2):91-8.

11. Ashouri S, Nili-Ahmadabadi M, Moradi M, Iranpour M. Semisolid microstructure evolution during reheating of aluminum A356 alloy deformed severely by ECAP. J Alloys Compd. 2008;466(12):67-72. http://dx.doi.org/10.1016/j.jallcom.2007.11.010.

12. Campo KN, Proni CTW, Zoqui EJ. Influence of the processing route on the microstructure of aluminum alloy A356 for thixoforming. Mater Charact. 2013;85:26-37. http://dx.doi. org/10.1016/j.matchar.2013.08.011.

13. Campo, K.N., Zoqui, E.J. Thixoforming of an ECAPed aluminum A356 alloy: microstructure evolution, rheological behavior, and mechanical properties. Metall Mater Trans, A Phys Metall Mater Sci. 2016;47A(4):1792-802. http://dx.doi.org/10.1007/ s11661-016-3339-4.

14. American Society for Testing and Materials. B179-14: standard specification for aluminum alloys in ingot and molten forms for castings from all casting processes. West Conshohocken: ASTM International; 2014. https://doi.org/10.1520/B0179-14.

15. Zoqui EJ, Paes M, Es-Sadiqi E. Macro- and microstructure analysis of SSM A356 produced by electromagnetic stirring. J Mater Process Technol. 2002;120(1-3):365-73. http://dx.doi. org/10.1016/S0924-0136(01)01148-7.

16. Laxmanan, V.; Flemings, M.C. Deformation of semisolid Sn-15\%Pb alloy. Metall Trans, A, Phys Metall Mater Sci. 1980;11A:1927-37. http://dx.doi.org/10.1007/BF02655112.

17. American Society for Testing and Materials. E112-13: standard test methods for determining average grain size. West Conshohocken: ASTM International; 2013. https://doi.org/10.1520/E0112-13.

18. Czerwinski F. Thermomechanical processing of metal feedstock for semisolid forming: a review. Metall Mater Trans, B, Process Metall Mater Proc Sci. ;49(6):3220-57. http://dx.doi.org/10.1007/ s11663-018-1387-4.

19. Kang, C.G., Choi, J.S., Kim, K.H. Effect of strain rate on macroscopic behavior in the compression forming of semisolid aluminum alloy. J Mater Process Technol. 1999;88(1):159-68. http://dx.doi.org/10.1016/S0924-0136(98)00383-5. 